\title{
Article Review of three case studies showing the common factors of burnout the school counselors come across in different interval period
}

\author{
Article by Fides A. Urbiztondo \\ B.Sc. ECE Texila American University, Egypt \\ Email: fidesurbiztondo@gmail.com
}

\section{Sources}

Falls, Leigh and Nichter, Mary (2007). "The voices of HS Counselors: Lived experience of job stress". Journal of School Counseling, v5 N13 2007. Retrieved on 7/22/2015; http://files.eric.ed.gov/fulltext/EJ901174

Windle, Michele Hurt (2009), "Counseling Matters: A multi-case study of High School counselors and their role in the school community". Retrieved on 07/22/2015; http://www.repository.lib.ncsu.edu/ir/bitstream/1840.16/5060/1/etd.pdf

Moyer, Michael (2011). "Effects of non-guidance activities, supervision, and studenttocounselor ratios on school counselor burnout". Journal of School Counseling, v9 N5 2011. Retrieved on 7/22/2015; http://jsc.montana.edu/articles/v9n5.pdf

\section{Introduction}

The article review discusses three studies that examine the factors lead to burnout which experienced by the school counselor in different time interval. In the Journal School of Counseling article " The voices of High School Counselors: lived experiences of job stress ", Leigh Falls and Mary Nichter (2007) suggested school counselors commonly experience situations of high demand and low control, due to the complex and diverse nature of the work they perform. In the NCSU libraries article, "Counseling Matters: a multi-case study of high school counselors and their role in the school community", as the findings of Michelle Hurt Windle (2009) suggested that high school counselors had experience an overloaded with noncounseling related duties and expected to serve far too many students. The results presented by Michael Moyer (2011) in the Journal of School Counseling article "Effects of nonguidance activities, supervision, and the ratios of student-to-counselor school counselor burnout, indicated that the greater amount of time spent on non-guidance duties, the greater it significantly affects school counselor burnout. Also, school counselors often experience of low self-efficacy due to lack of support, role ambiguity, role conflicts and workloads which caused burnout from the school counselors' profession. All of the article imply that several factors such as large caseloads, role ambiguity, non-guidance activities and lack of time spent on counseling duties lead to burnout. All of the article imply that several factors such as large caseloads, role ambiguity, nonguidance activities and lack of time spent on counseling duties lead to burnout. Most of the studies presented the same factors in different period that confirmed the causes of school counselor burnout. Each study has weakness that include bias, contradiction and limits of the study.

\section{Objective of the article review}

In this study the information was objective developed, well support with a current research based and with all evidence acknowledged and referenced. There is an evidence of bias. The article acknowledged the complexity of the issues discussed in a number of ways with reference to the three case studies. School counseling is a vocation in which emotional empathy is a prerequisite and the type or kind and number of job demands are high. Stressors associated to burnout have effects that may continue even after exposure to the stressor has ended, leading to 
South American Journal of Academic Research

Special Edition May 2016

undesirable impact on well-being. The purpose of this article review is to reflect and recollect the different case studies that brought to light the issue of burnout that focused more on to the school counselor which still exist up to this date. The participants and the evaluation and findings were clearly defined.

\section{Background}

Two main keywords, burnout and school counselor, are discussed in this section. By definition extracted from Wikipedia about burnout where it is a psychological term that discusses to longterm exhaustion and reduced interest in work. Burnout had been assumed to result from continuing work-related stress such as work surplus. Burnout is becoming a more common results as the modern workplace changes. The increasingly intimidating and demanding environment in which employees work is being studied as a cause by both economically and psychologically exhaustion. More frequently, the economic values are much more considered than that of human values. The incident is more likely when a discrepancy is present between the nature of the job and the person doing the job. A common indication of this discrepancy is work overload. It involves doing too much with too few means, going beyond human boundaries. This may occur in a situation of reduction or downsizing, which often does not reduce company's mandate, but allocates it to present employees. Typical causes of burnout resulted directly from work, such as lack of recognition for good work, feeling of no control over one's work, and unclear and overly demanding expectation. Burnout may sound a lot like stress, it is important to realize that it is not the same characterization. Stress is categorized by over involvement, burnout is characterized by detachment. Stress ultimately produces determination and hyperactivity, whereas burnout produce helplessness and hopelessness. Although, stress my cause a loss of vigor and develops anxiety disorder, on the other hand burnout often involves loss of motivation, ideas, hope and aspiration.

School counselors is an essential part of any school organization in the elementary, middle and high school grade levels. They are supporters in the students' whole being because they direct guidance of both their own and school life. School counselors make regular assessments of the students' performance and improvement. This enables them to measure their individual requirements and every so often checking with students regarding their future career choices. The school counselor's role is a vital part of influencing the individuality of the students. Job responsibilities differ depending on the education level they are in. Generally, they are students' believers.

\section{Summary of case studies}

This section provides a quick glance of each study. All of the studies varied in the subjects and methods used. The first study illustrates the job stress phenomenon in the counselors' own views, identifier situation (role uncertainty, role struggle and work overload) contributing to job stress. After two years another study addresses issues of school counselors have in common, their job outlooks and how those issues contribute to their specialized self efficacy. The last study after another two years interval determined that guidance related duties and supervision are the best predictions of burnout.

In "The voice of high school counselors: live experience of job stress", conducted a qualitative study. Four high school counselors, 1 male and 3 female; 2 Caucasian and 2 African American, from two high schools were interviewed. The interview was an openended question in order to encourage the participants to describe what was significant and noteworthy to them in their own experiences of job related strain. Researcher triangulation was incorporated by having two researchers independently review and code the data. Job stress includes situations involving high external demands for principals, teachers, parents or students and low personal control regarding how their time is spent. Role uncertainty exists when the counselor's perception of his or her role 
and that of external stakeholders are inconsistent. School counselors experience role conflict when they are expected to complete two or more tasks simultaneously, often lacking the necessary resources to complete two or more tasks simultaneously, often lacking the necessary resources to complete their expected task.

"Counseling Matters: A multi case study of high school counselors and their observations of their role in the school community conducted a qualitative research through an empirical case study research of six participating high school counselors from five Wake County high school where each school somewhat different from the others. There were 3 male and 3 female; four Caucasian and two African American. Open-ended questions were investigated to study the phenomenon of counselors' perceived role, daily activities, goals and overall thoughts about their jobs. The issues tackled as follows: 1) role definition and administration support in which the participants indicated that their duties were not always clearly defined, and were not always reflective of their written job descriptions; 2) time and caseload wherein the study participants' caseload range from 450-600 students which is above the number recommended by the ASCA ratio as 250:1; c) expectations as counselors participating in this study talked about a shift in thinking as they face new accountability requirement; d) impact on professional self-efficacy; further discussed the impact of the daily situations they experience as high school counselors as they reflected on their beliefs about what makes a good counselor, their own feeling of effective and success and their overall satisfaction in the profession.

In "Effects of non-guidance activities, supervision, and student-to-counselors ratios on school counselor burnout" conducted categorized multiple regression analyses. Web-based surveys were sent to ASCA's regional and state representatives and total of 382 counselors completed the survey. Of the 382 respondents, 52 were male, 325 female and 5 unknown; 111 participants worked in elementary school settings, 85 in middle school, 128 in high school settings and 58 unknown. From the hierarchical regression analysis summary for variables predicting school counselor burnout from the six model all of which the non-guidance duties accounted significant portion while the supervision 4 out of 6 models accounted significant portion.

\section{Implications of case studies}

This section discusses the implications of these studies. The need for some collaborative planning among counselors as they strive to contribute to students' academic, personal and career development while can currently struggling with the ever increasing demands of their jobs. Also school administrators may need to look to their counseling staff for ways to be better informed about the characteristics of a comprehensive school counseling program as the array of service a qualified counselor can realistically provide in a school. School counselors need to highlight the success of their program and connect their program goals to the mission and goals of the school are better able to define their role. When it comes to supervision, school counselors need to receive adequate supervision to feel more competent in their duties and it provides school counselors with an avenue to vent frustrations that come about that may help increase empathy for students. School counselor's education program should make adjustments to more closely reflect real life demands experienced by school counselors, rather than relying solely on teaching theory and counseling skills. Providing information to parent and students regarding the appropriate role of the counselor may lessen the burden on counselors expected to do therapy with students or who are expected to change schedules in order to facilitate the parent, student and administration or teacher from having to address interpersonal conflicts.

\section{Evaluation \& limitation}


This section evaluates the quality of each study. Some of the studies have a strong features that are worth mentioning. Each of these studies have at least one weakness that pull down the value of their findings. The earliest study used an open ended questionnaire and researcher triangulation was incorporated. Another study used a demographic questionnaire and to further validate the study through triangulation. The latest study made through webbased surveys as regression models were chosen because the primary focus of the article is predicting the effect of the three identified predictor variables. With the instruments used, two studies may not be conclusive with their findings due to the size of the participants and the other study due to all participants were member of the same organization. Comparison of three studies in two years interval reflected that the same problem will be observed in the coming years of the school counselors' career. If ever burnout or job stress was experienced by the school counselors their advocacy to their students keep their motivation in place at the end of the day.

\section{Conclusion}

School counselors often come into profession with their own idealized version of counseling. School districts often do not have clearly identified counseling duties, leaving administrators who have little, if any, understanding of the school counseling function to assign duties they think are appropriate such as testing, scheduling, and monitoring class size. Among other administrators, teachers, and parents often have conflicting beliefs about the school counselor's role, resulting in an overwhelming demand on the counselor's time with limited resources available to perform at optimal levels. Counselor may aid their own efforts to avoid non-guidance activities by advocating for their position and responsibilities. School counselors who firmly establish their role within the school maybe surrendered from unnecessary non-guidance take and free to explore other ways to benefit the students with their school. Supervision provides confirmation to counselor that they are performing appropriately in their role and also gives mentorship regarding ways to effectively handle job stress. Several recommendations of different time interval however were jammed somewhere for no progress and the issues of burnout still experienced by most of the school counselors. 